Check for updates

Cite this: RSC Adv., 2018, 8, 21566

Received 23rd April 2018 Accepted 28th May 2018

DOI: $10.1039 / c 8 r a 03497 d$

rsc.li/rsc-advances

\section{Robust colorimetric detection based on the anti-aggregation of gold nanoparticles for bromide in rice samples $\uparrow$}

\author{
Siwat Plaisen, ${ }^{\text {ab }}$ Wilairat Cheewasedtham (DD ${ }^{b}$ and Thitima Rujiralai (D) *ab
}

Inorganic bromide $\left(\mathrm{Br}^{-}\right)$is an important contaminant ion as it can originate from the overuse of illegal methyl bromide as a fumigant in stored rice samples. Herein, we developed a simple and highly sensitive colorimetric sensor for bromide ion detection in rice samples. The sensor is based on the antiaggregation of gold nanoparticles (AuNPs) by $\mathrm{Br}^{-}$in the presence of $\mathrm{Cr}^{3+}$, which made the method more selective than other typical aggregations of nanoparticles. The AuNPs underwent an aggregation process as a result of the coordination of $\mathrm{Cr}^{3+}$ and the carboxylate group of a citrate ion stabilized the AuNPs, resulting in a red-to-blue color change. When $\mathrm{Br}^{-}$was pre-mixed with the AuNPs and $\mathrm{Cr}^{3+}$ was added, the solution color changed from blue to red with an increase in the $\mathrm{Br}^{-}$concentration. The antiaggregation process can be detected with the naked eye and monitored using UV-vis spectrophotometry. The linear calibration curve ranged between 0.31 and $3.75 \mu \mathrm{M} \mathrm{Br}^{-}$with a low LOD and LOQ of 0.04 and $0.13 \mu \mathrm{M}$. The recovery was excellent, ranging from $79.9-92.2 \%$ with an RSD of less than $4.0 \%$. The good inter-day and intra-day precisions were $2.9-6.4 \%$ and $3.1-7.1 \%$, respectively. The developed sensor has proved to provide a robust method for $\mathrm{Br}^{-}$detection in rice samples.

\section{Introduction}

Methyl bromide $\left(\mathrm{CH}_{3} \mathrm{Br}\right)$ is a fumigant that is often used for controlling a variety of pests such as insects, mites, moulds, nematodes, weeds, viruses and bacteria, as well as being used in soil disinfection and as a postharvest treatment for stored and dried foodstuffs including rice, tobacco, fresh fruits and vegetables. ${ }^{1-3}$ It is dominant over other fumigants due to the fact it is a colorless, odorless (at low concentrations) and non-flammable gas with a high rate of penetration. ${ }^{2-4}$ Its toxic effects on human health are (following short-term exposure) headache, dizziness, nausea, vomiting, blurred vision, slurred speech and convulsions. High concentrations of methyl bromide may cause unconsciousness and death. Prolonged exposure to methyl bromide may cause injury to the central nervous system. ${ }^{4}$ Furthermore, it can greatly destroy the ozone layer through emission from agricultural pesticide use, from the burning of biomass and leaded gasoline, and from the ocean. ${ }^{5,6}$ Thus, the use of methyl bromide is controlled by many organizations and

${ }^{a}$ Department of Chemistry, Center of Excellence for Innovation in Chemistry, Faculty of Science, Prince of Songkla University, Hat Yai, Songkhla, 90112 Thailand. E-mail: thitima.r@psu.ac.th

${ }^{b}$ Analytical Chemistry and Environment Research Unit, Division of Chemistry, Department of Science, Faculty of Science and Technology, Prince of Songkla University, Pattani, 94000, Thailand

$\dagger$ Electronic supplementary information (ESI) available. See DOI: $10.1039 / \mathrm{c} 8 \mathrm{ra03497d}$ it is already being phased out. From January 12005 , the production and use of methyl bromide will be stopped in the U.S.A. with exemptions for emergency and critical use. ${ }^{5-7}$ The agricultural use of methyl bromide in China will also be terminated at the end of $2018 .^{8}$ The application of methyl bromide in the European Union has been forbidden since 2010, but exceptions are made, especially with regard to the International Standards for Phytosanitary Measures $15 .^{9}$

After food commodities are fumigated, methylated products and inorganic bromide are formed as a result of chemical reactions with some of the constituents of the treated foodstuffs or the breakdown products of methyl bromide..$^{1-3,10,11}$ Inorganic bromide has been detected in rice and glutinous rice in the ranges $0.13-11.93 \mathrm{mg} \mathrm{kg}^{-1}$ and $0.20-1.37 \mathrm{mg} \mathrm{kg}^{-1}$, respectively, and its concentration in all samples were within the Codex maximum residue limit value of $50 \mathrm{mg} \mathrm{kg}^{-1} .^{2}$ Methyl bromide residues can persist in nuts and seeds for 10 weeks and in dried fruit for 4 weeks. ${ }^{1}$ Cova et al. reported that higher concentrations of bromide ions were detected in fumigated pastas with eggs, pastas with eggs and spinach, and rice compared to in those that were unfumigated. ${ }^{\mathbf{1 1}}$

Thailand, as the world's leading rice producer and also one of the largest rice consumers, imported an average of 357.69 and 103.85 tons per year of methyl bromide and a mixture between methyl bromide and chloropicrin, respectively, to eliminate undesired pests before commercializing their products between 2007 and 2012. ${ }^{2}$ Due to its toxicity, under the agreement of the Montreal Protocol, Thailand agreed to 
gradually reduce and to phase out the use of methyl bromide by 2015. ${ }^{12}$ The Thai Ministry of Public Health has defined the maximum residue limit (MRL) of methyl bromide in rice as $0.01 \mathrm{mg} \mathrm{kg}^{-1}$ and of bromide ions in rice as $50 \mathrm{mg} \mathrm{kg}{ }^{-1} \cdot{ }^{13} \mathrm{In}$ 2013 , methyl bromide was not detected in any rice samples $(n=$ 13), however the bromide ion concentration in one sample was detected to be $77.2 \mathrm{mg} \mathrm{kg}^{-1}$ and after 4 days its concentration had decreased to $20.9 \mathrm{mg} \mathrm{kg}^{-1} .^{14}$

Due to food globalization, rice consumption is also increasing around the world. The determination of methyl bromide and inorganic bromide contamination in rice is, therefore, required as a method for guaranteeing consumer safety. In most cases, bromide ion contamination in rice has been found when food commodities are fumigated with either low or high concentrations of methyl bromide, and are particularly over the limit when they have been fumigated with methyl bromide multiple times. ${ }^{\mathbf{1 - 3 , 1 1 , 1 4 , 1 5}}$ Many studies have also focused on inorganic bromide in food in order to assess the daily intake of bromide ions from food and water into the human body. ${ }^{10,16,17}$ Therefore, bromide ions are the main target analyte for this work, whether from the accumulation of bromide ions from the environment or from the transformation of methyl bromide.

Prior to the detection step, bromide ions in foodstuffs have been treated using different procedures e.g., low energy microwave digestion, ${ }^{16}$ high temperature heating $\left(\sim 850{ }^{\circ} \mathrm{C}\right),{ }^{18}$ hydrolysis with alkaline and ashing at $550{ }^{\circ} \mathrm{C},{ }^{2}$ and suspension in $6 \mathrm{~N}$ sulfuric acid and propylene oxide followed by extraction with ethyl acetate. ${ }^{15}$ Subsequently, the pre-treated samples are determined using sophisticated instrumentation such as inductively coupled plasma-mass spectrometry, ${ }^{16}$ gas chromatographyelectron capture detecting, ${ }^{2,15}$ and ion-exchange chromatography with visible light detection. ${ }^{19}$ However, these mentioned instrumentations require not only complex sample preparation and long analysis times but also complicated and expensive instruments.

Nowadays, gold nanoparticle (AuNP)-based colorimetric sensors have drawn increasing attention due to their low cost and their rapid, selective and reliable detection. ${ }^{20-23}$ In general, AuNPs change from the dispersion to the aggregation state and their color changes from ruby red to purple or blue. ${ }^{20-23}$ An absorption band in the visible range with a high extinction coefficient (e.g., $\left.2.70 \times 10^{8} \mathrm{M}^{-1} \mathrm{~cm}^{-1}\right)^{23}$ appears when the incident photon frequency resonates with the excitation of the conduction electrons. This phenomenon is named surface plasmon resonance (SPR). ${ }^{20-23}$ Due to these advantages, AuNPs can be used as a powerful tool for real-time monitoring via naked-eye detection, rather than using any advanced instruments. AuNPs have also been applied for the detection of ions, ${ }^{20-22,24-28}$ gas $^{29}$ and organic residues ${ }^{30-34}$ such as $\mathrm{Hg}^{2+}, \mathrm{Cu}^{2+}, \mathrm{S}^{2-}, \mathrm{I}^{-}, \mathrm{SCN}^{-}, \mathrm{H}_{2} \mathrm{~S}$, clenbuterol, aflatoxins, tetracycline, amoxicillin and pazufloxacinmesilate, in which the detection mostly depends on the aggregation. It was reported that AuNP aggregation is not selective and can provide false positive results due to the effects of many other external factors in real applications. Thus, the anti-aggregation or redispersion of AuNPs has become a good option to utilise in order to improve selectivity. ${ }^{21,22,25,27,29}$
So far, a colorimetric probe based on the AuNP antiaggregation process has not been found for bromide ion determination in rice samples. In this work, we developed a AuNP colorimetric sensor for the facile, sensitive and selective detection of bromide ions in rice samples. The sensor is based on the fact that bromide ions prevent the aggregation of AuNPs. The addition of $\mathrm{Cr}^{3+}$ into a AuNP solution resulted in the aggregation of AuNPs with a red-to-blue color change. In the presence of $\mathrm{Br}^{-}$, the aggregation of AuNPs was interrupted and the corresponding color of solution changed from blue to red. The concentration of bromide ions in real samples can be easily observed with the naked eye, and also quantitatively measured using UV-visible spectroscopy.

\section{Material and methods}

\subsection{Chemical and reagents}

All chemicals were of analytical grade. Gold(III) chloride trihydrate $\left(\mathrm{HAuCl}_{4} \cdot 3 \mathrm{H}_{2} \mathrm{O}\right)$ was purchased from Sigma-Aldrich (USA). Chromium(III) nitrate nanohydrate was purchased from AlfaAesar (USA). Trisodium citrate and disodium hydrogenphosphate dodecahydrate were purchased from Ajax Finechem (Australia). Hydrochloric acid, potassium hydroxide, ethanol and nitric acid were purchased from RCI Labscan (Thailand). Potassium bromide and sodium dihydrogen phosphate dehydrate were purchased from LobaChemi (India). All solutions were prepared using $18 \mathrm{M} \Omega \mathrm{cm}^{-1}$ ultrapure water obtained from ELGA Maxima.

Sodium phosphate buffer ( $\mathrm{pH} 6.5$ at $0.01 \mathrm{M}$ ) was prepared by mixing $34 \mathrm{~mL}$ of $0.02 \mathrm{M}$ sodium dihydrogenphosphate and $16 \mathrm{~mL}$ of $0.02 \mathrm{M}$ disodium hydrogenphosphate. Subsequently, the buffer was adjusted by either sodium dihydrogenphosphate or disodium hydrogenphosphate to obtain a $\mathrm{pH}$ of 6.5 and the volume was made up to $100 \mathrm{~mL}$ with ultrapure water. A stock solution of $12.52 \mathrm{mM}$ bromide ion was prepared from potassium bromide. It was necessary that all the glassware was thoroughly cleaned in freshly prepared aqua regia solution $(3: 1$ $\mathrm{v} / \mathrm{v} \mathrm{HCl}-\mathrm{HNO}_{3}$ ), washed with ultrapure water at least twice and then oven-dried at $150{ }^{\circ} \mathrm{C}$ before use to avoid aggregation of gold colloids due to any contaminants.

\subsection{Synthesis of gold nanoparticles (AuNPs)}

The gold nanoparticles (AuNPs) were synthesized via the trisodium citrate reduction of $\mathrm{HAuCl}_{4}$ according to the previous method with slight modification. ${ }^{20}$ A volume of $250 \mathrm{~mL}$ of $0.015 \%(\mathrm{~m} / \mathrm{v}) \mathrm{HAuCl}_{4}$ solution was added into a $500 \mathrm{~mL}$ Duran bottle and was heated to boiling with vigorous stirring. Subsequently, $8.75 \mathrm{~mL}$ of $1 \%(\mathrm{w} / \mathrm{v})$ trisodium citrate solution was added rapidly into the boiling solution followed by stirring. The color of the solution changed from pale yellow to wine red in a few minutes as $\mathrm{Au}^{3+}$ was reduced to $\mathrm{Au}^{0}$, indicating the formation of citrate-capped gold nanoparticles (AuNPs). After that, the AuNP solution was continuously boiled for another $15 \mathrm{~min}$ to ensure the reaction was completed. It was then allowed to cool down to room temperature under stirring, and the volume was adjusted to $250 \mathrm{~mL}$ with ultrapure water in 
a volumetric flask. The spectrum of this synthesized AuNP solution was investigated. For further study, this AuNP solution was stored in an amber bottle at $4{ }^{\circ} \mathrm{C}$. After synthesis, the maximum absorbance of the AuNP solution was 1.49 at a surface plasmon resonance (SPR) wavelength of $519 \mathrm{~nm}$ with a calculated particle concentration of $5.52 \mathrm{nM}$ (Fig. S1 (ESI $\dagger$ )), according to Beer's law using an extinction coefficient of $2.70 \times$ $10^{8} \mathrm{M}^{-1} \mathrm{~cm}^{-1}$. ${ }^{23}$ We have proved that AuNPs synthesized via the above method can be kept in a fridge for up to 4 months without any loss of sensitivity together with an absorbance of $1.49 \pm 0.01$ at $519 \mathrm{~nm}$ (Fig. S2 (ESI $\dagger$ )).

\subsection{Characterization}

The surface plasmon resonance (SPR) spectra of the synthesized AuNP solution were investigated in the range $400-800 \mathrm{~nm}$ using a UV-1800 spectrophotometer (Shimadzu, Japan) in a $1.5 \mathrm{~mL}$ disposable polystyrene cuvette. The size and shape of the AuNPs were measured using a transmission electron microscope (TEM, JEM-2010, JEOL, Japan) with a $200 \mathrm{kV}$ acceleration voltage. Before TEM measurements, the samples were diluted 3 times with ultrapure water before deposition and $5 \mu \mathrm{L}$ of the diluted sample was deposited on the carbon-coated copper grid and then evaporated at room temperature. Moreover, the zetapotential value and size distribution of the synthesized AuNP solution were studied using a zeta potential analyzer (ZetaPALS, Brookhaven, USA).

\subsection{Colorimetric determination of bromide ions}

To increase the selectivity of the developed method, the determination of the bromide ions in this study was based on the anti-aggregation of AuNPs. A volume of $100 \mu \mathrm{L}$ of different concentrations of $\mathrm{Br}^{-}$was first added to $400 \mu \mathrm{L}$ of $5.52 \mathrm{nM}$ AuNP solution containing $500 \mu \mathrm{L}$ of $10 \mathrm{mM}$ phosphate buffer solution (pH 6.5), and the mixture was mixed well using a vortex mixer. After that, $100 \mu \mathrm{L}$ of $57.70 \mu \mathrm{M} \mathrm{Cr}^{3+}$ was added to the mixture with vortex mixing and the solution was incubated for $10 \mathrm{~min}$ at room temperature $\left(25 \pm 2{ }^{\circ} \mathrm{C}\right)$ to allow for adequate reaction time and to ensure the color had completely developed. After interaction, the color of the solution was observed with the naked eye. Photographs of the resulting solution were taken and the UV-visible spectra of the mixtures from $400-800 \mathrm{~nm}$ were recorded immediately. The spiked samples for recovery in pretreated samples were investigated using the same procedure.

\subsection{Sample preparation of rice}

White rice samples (five commercial brands) were collected randomly from a supermarket in the Hat Yai district, Songkhla province, Thailand and stored in a refrigerator at $4{ }^{\circ} \mathrm{C}$ before the experiment. The rice sample was prepared according to the report of Sungwaranond et al. with modifications. ${ }^{2}$ The rice sample $(100 \mathrm{~g})$ was ground using a Ball mill (Retsch MM400, Germany) to obtain a powder $(\sim 5 \mu \mathrm{m})$.

Two grams of the rice powder was added into a $50 \mathrm{~mL}$ nickel crucible and digested with $5 \mathrm{~mL}$ of $1 \%$ potassium hydroxide in $50 \%$ ethanol. The sample was boiled on a hotplate (by gradually increasing the heating rate to avoid the sample bumping) until it was dry and no smoke was observed. Next, it was burned in a muffle furnace at $600{ }^{\circ} \mathrm{C}$ for $4 \mathrm{~h}$ to eliminate the organic residues in the rice samples. After the obtained ash was allowed to cool down, $15 \mathrm{~mL}$ ultrapure water was added and the solution was boiled for $15 \mathrm{~min}$ on a hotplate in order to dissolve the inorganic bromide, and was filtered with a $0.22 \mu \mathrm{m}$ Nylon membrane through a $25 \mathrm{~mL}$ volumetric flask. The ash residue was placed in a nickel crucible and was again boiled using another $10 \mathrm{~mL}$ ultrapure water. This new solution was filtered through the previous volumetric flask and finally diluted with ultrapure water up to the mark. The sample solution was then diluted 1 fold with ultrapure water before the color reaction was performed.

\subsection{Optimization of the colorimetric detection of bromide ions}

To obtain the best sensitivity of the method, the analytical conditions for the detection of $\mathrm{Br}^{-}$, i.e., the concentration of $\mathrm{Cr}^{3+}$, the $\mathrm{pH}$ and concentration of the phosphate buffer, the concentration of the AuNPs and the reaction time, were optimized. Each parameter was studied using a one step at a time experiment. All experiments were repeated three times with the results reported as mean \pm standard deviation (SD). The absorbances at 519 and $673 \mathrm{~nm}$ were found to be directly related to the dispersed, aggregated and anti-aggregated states of the AuNPs. Therefore, the absorbance intensity ratio of $A_{519} / A_{673}$ was used for the quantitative determination of $\mathrm{Br}^{-}$. In order to obtain a representative sample for method development and optimization, five different brands of rice were mixed together. All the statistical analyses were performed using Microsoft Office Excel 2007. The ANOVA at a 95\% confidence level was used for data analysis.

\section{Results and discussion}

\subsection{Proposed sensing mechanism}

Fig. 1 shows the proposed mechanism for the successful colorimetric sensor of bromide ions based on the antiaggregation of AuNPs. The AuNP solution presented a maximum SPR absorption at $519 \mathrm{~nm}$ (Fig. 2a) with a red wine color (Fig. 1), which was in good agreement with previous reports. $^{20-22}$

In this study, sodium citrate could act as a reductant and a stabilizer of colloidal AuNPs. Thus, the AuNPs were relatively stable due to the strong electrostatic repulsion between the negatively charged citrate ions on the surface of the AuNPs. ${ }^{35,36}$ It was reported that $\mathrm{Cr}^{3+}$ could coordinate with two citrate ions via the hydroxyl groups in each citrate ion with a high formation constant of $3.89 \times 10^{29} .^{37,38}$ Thus, citrate can also be used as the ligand for interaction with $\mathrm{Cr}^{3+}$, and $\mathrm{Cr}^{3+}$ can serve as a cross linking agent between the pairs of citrate-coated AuNPs. ${ }^{36}$ This ligand exchange is probably strong enough to overcome the electrostatic repulsion imposed by the citrate-AuNPs, thus inducing the aggregation of the AuNPs.

Upon addition of $\mathrm{Cr}^{3+}$ (Fig. 1A), the intensity of the SPR band of the AuNPs at $519 \mathrm{~nm}$ decreased, and a new absorption band 

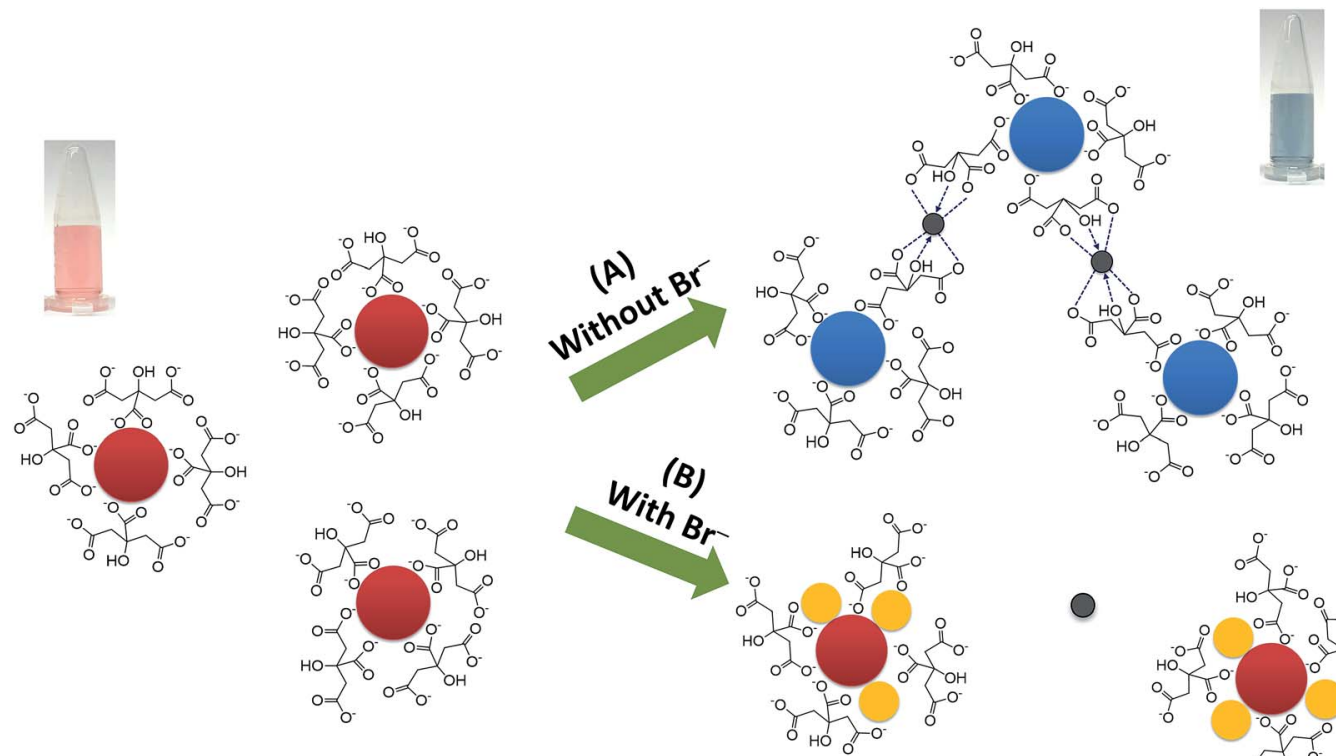
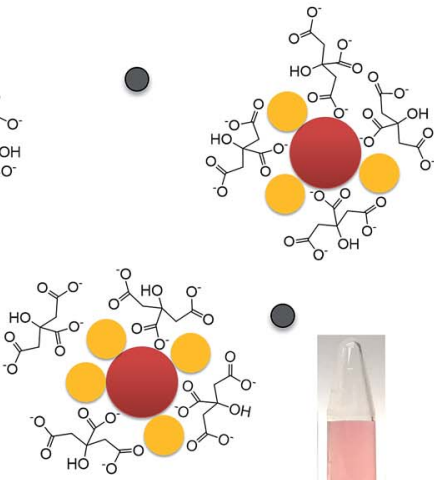

Fig. 1 A proposed mechanism for the colorimetric sensor of bromide ions based on the anti-aggregation of AuNPs.

appeared at $673 \mathrm{~nm}$ (Fig. 2b) due to the AuNP aggregation driven by $\mathrm{Cr}^{3+}$, demonstrating the successful conjugation of $\mathrm{Cr}^{3+}$ with the AuNPs. This caused a red-to-blue color change. The result of the aggregation was also confirmed via TEM measurement (Fig. 3A). We observed a spherical monodisperse colloid of individual AuNPs before aggregation (Fig. 3A(a)). The average particle size of the prepared AuNPs was $16.43 \pm$ $0.81 \mathrm{~nm}$. In the presence of $\mathrm{Cr}^{3+}$ (Fig. 3A(b)), heavy aggregation of the AuNPs was observed, confirming that $\mathrm{Cr}^{3+}$ induced largescale aggregation of the AuNPs through chelating reactions, resulting in the particle size distribution of the aggregated AuNPs in the presence of $\mathrm{Cr}^{3+}$ being about 16 times higher than those without $\mathrm{Cr}^{3+}$ (calculated from the size ratio of 262.30/

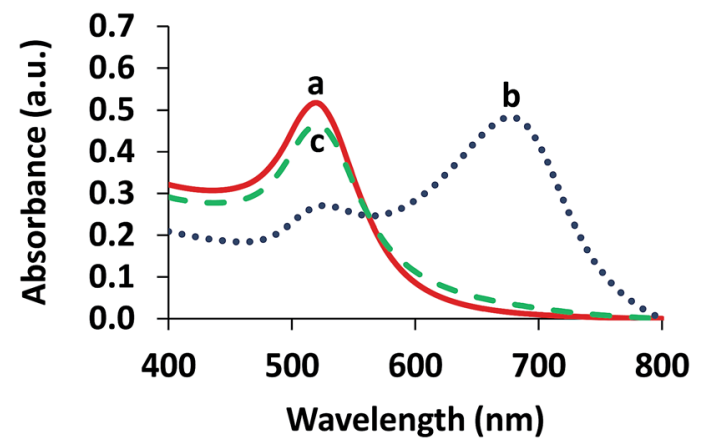

Fig. 2 UV-vis absorption spectra of (a) AuNPs, (b) aggregation of the AuNPs in the presence of $4.80 \mu \mathrm{MCr}^{3+}$ and (c) anti-aggregation of the AuNPs in the presence of $3.13 \mu \mathrm{M} \mathrm{Br}^{-}$and $4.80 \mu \mathrm{M} \mathrm{Cr}^{3+}$.

16.43 in Fig. $3 \mathrm{~B}(\mathrm{~d}$ and e)). A similar phenomenon of aggregation was also reported by Liu and Wang. ${ }^{39}$

When the AuNPs were treated with $\mathrm{Br}^{-}$followed by mixing with $\mathrm{Cr}^{3+}$ (Fig. 1B), the color of the AuNPs was found to successfully change from blue to wine red, along with

(A)

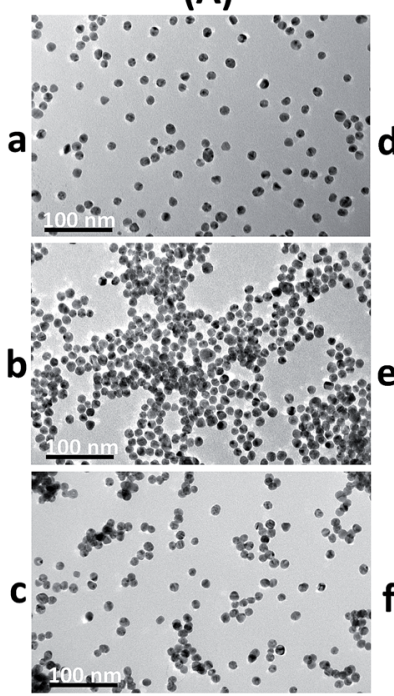

Fig. 3 (A) TEM images and (B) particle size distributions of (a) and (d) AuNPs, (b) and (e) aggregation of the AuNPs in the presence of $4.80 \mu \mathrm{M}$ $\mathrm{Cr}^{3+}$, and (c) and ( $\mathrm{f}$ ) anti-aggregation of the AuNPs in the presence of $3.13 \mu \mathrm{M} \mathrm{Br}^{-}$and $4.80 \mu \mathrm{M} \mathrm{Cr}^{3+}$. 
a decrease in the SPR absorption band at $673 \mathrm{~nm}$ and an increase in the band at $519 \mathrm{~nm}$ (Fig. 2c). This was called the anti-aggregation of the AuNPs, which was a result of the change of the AuNPs from the aggregation (blue color) to dispersion state (red color).

The anti-aggregation of the AuNPs could be caused by the adsorption of $\mathrm{Br}^{-}$onto the AuNP surface, leading to the prevention of aggregation driven by the $\mathrm{Cr}^{3+}$-citrate complex. The bromide ion is a chaotropic anion that can transfer its charge to the AuNP surface and thus, increase electrostatic stabilization. ${ }^{\mathbf{4 0}}$ Moreover, the adsorption of $\mathrm{Br}^{-}$on the surface of the AuNPs may prevent aggregation due to a higher stability constant of the $\mathrm{Au}$ $(1+$ or $3+)-\mathrm{Br}^{-}$complex, which is 12.3 and 32.8 for the $\mathrm{Au}^{+}-$and $\mathrm{Au}^{3+}-\mathrm{Br}^{-}$complex, respectively, ${ }^{41}$ compared to the lower stability constant of the $\mathrm{Cr}^{3+}-\mathrm{Br}^{-}$complex $(-2.66){ }^{42}$

The zeta potential values of the AuNPs after addition of 0.63 , 2.50 and $4.38 \mu \mathrm{M} \mathrm{Br}^{-}$were also investigated. As shown in Fig. S3 (ESI $\dagger$ ), the zeta potential values increased in proportion to the concentration of $\mathrm{Br}^{-}$, indicating that colloidal AuNPs are more highly electrically stabilized. The addition of $\mathrm{Br}^{-}$could stabilize the AuNP colloid and enhance the repulsion force between the AuNPs. This increased the repulsion force of each AuNP, which could affect the chelation between $\mathrm{Cr}^{3+}$ and citrate. As a result, the color of the solution remained red as the $\mathrm{Br}^{-}$concentration increased, relating to the increased dispersion state. The TEM confirmed the observation that the AuNPs remained dispersed with the addition of $\mathrm{Br}^{-}$and $\mathrm{Cr}^{3+}$, as well as confirming the decrease in size of the AuNPs compared to their size in the aggregation state as shown in Fig. 3A(c) and (f), respectively. Thus, it suggested that the effective anti-aggregation is induced by $\mathrm{Br}^{-}$.

\subsection{Optimization of colorimetric detection of bromide ions}

3.2.1 Concentrations of $\mathbf{C r}^{3+}$. The effect of different concentrations of $\mathrm{Cr}^{3+}$ in the range $0.96-19.23 \mu \mathrm{M}$ on the aggregation of AuNPs was investigated (Fig. 4A). With an increasing concentration of $\mathrm{Cr}^{3+}$, the color of the suspension gradually changed from red wine to purple and finally to blue, indicating a disruption to the stability of the citrate-capped AuNPs (Fig. 4A, inset picture). Initially, at a concentration of $0.96 \mu \mathrm{M} \mathrm{Cr}^{3+}$, the aggregation of the AuNPs was negligible since the excess amount of AuNPs provided a large number of binding sites and a better affinity for the citrate ion over $\mathrm{Cr}^{3+} \cdot 39$ At a concentration of $2.40-4.81 \mu \mathrm{M} \mathrm{Cr}^{3+}$, the aggregation was enhanced, which can be seen in the colour change from a purple to a blue solution. This may be attributed to the fact that the binding sites of the citrate ion on the surface of the AuNPs were occupied by $\mathrm{Cr}^{3+}$, leading to aggregation.

These results reveal the sharp decrease in the absorbance ratio of $A_{519} / A_{673}$ of $0.96-4.81 \mu \mathrm{M} \mathrm{Cr}^{3+}$ (Fig. $4 \mathrm{~A}$ ). At a concentration of $\mathrm{Cr}^{3+}$ higher than $4.81 \mu \mathrm{M}$, the ratio became stable, indicating the maximum degree of aggregation. By considering the lowest concentration of $\mathrm{Cr}^{3+}$ that provided the maximum degree of aggregation, $4.81 \mu \mathrm{M} \mathrm{Cr}^{3+}$ was chosen as the optimal concentration.

Although $\mathrm{Cr}^{3+}$ is a toxic substance, it is considered as an essential trace element and is less toxic than $\mathrm{Cr}^{6+}$, since $\mathrm{Cr}^{6+}$ has high solubility and mobility in biological systems. ${ }^{\mathbf{4 3}}$ The selected concentration of $\mathrm{Cr}^{3+}$ (equal to $4.81 \mu \mathrm{M}$ or $5.76 \mathrm{nmol}$ $\mathrm{Cr}^{3+}$ ) used in our test was very low.

Moreover, we have investigated other non-toxic substances such as $\mathrm{Fe}^{3+}$ and $\mathrm{Al}^{3+}$ for use as aggregation reagents as shown in Fig. S4 (ESI $\dagger$ ). This showed that at the same concentration of ions, $\mathrm{Cr}^{3+}$ provided heavy aggregation of citrate-stabilized gold nanoparticles but $\mathrm{Fe}^{3+}$ and $\mathrm{Al}^{3+}$ did not aggregate AuNPs. The optimization of the $\mathrm{pH}$ of the phosphate buffer in the range 6.08.0 in the presence of $\mathrm{Cr}^{3+}, \mathrm{Fe}^{3+}$ and $\mathrm{Al}^{3+}$ was also carried out (Fig. S5 (ESI $\dagger$ )). Only $\mathrm{Cr}^{3+}$ gave the response of aggregation of the AuNPs. These two investigations confirmed that $\mathrm{Cr}^{3+}$ is more specific for $\mathrm{Br}^{-}$detection than other aggregation reagent ions $\left(\mathrm{Fe}^{3+}\right.$ and $\left.\mathrm{Al}^{3+}\right)$.

3.2.2 $\mathrm{pH}$ of solution. The $\mathrm{pH}$ of solution affected the antiaggregation system between $\mathrm{Br}^{-}$and the AuNPs, and thus influenced the $A_{519} / A_{673}$ ratio. The phosphate buffer was chosen due to its high solubility in water and high buffering capacity in the studied range. Fig. 4B shows the effect of the $\mathrm{pH}$ values $(6.0$ to 7.5) of the phosphate buffer on the sensitivity to $\mathrm{Br}^{-}$ concentration in the range $0.63-5.01 \mu \mathrm{M}$. This sensitivity value was the slope of linearity plotted between the $A_{519} / A_{673}$ ratio $(y$ axis) and the $\mathrm{Br}^{-}$concentration ( $x$ axis) as shown in Fig. S6 (ESI $\dagger$ ). The result showed that the sensitivity of bromide detection increased when the $\mathrm{pH}$ of the buffer increased from 6.0 to 6.5 (Fig. 4B) and the corresponding solution changed color from blue to red (Fig. S6 (ESI $\dagger$ )).

It is known that the $\mathrm{p} K_{\mathrm{a} 1}, \mathrm{p} K_{\mathrm{a} 2}$ and $\mathrm{p} K_{\mathrm{a} 3}$ values of citric acid are $3.2,4.8$ and 6.4 , respectively. ${ }^{38,44}$ When the $\mathrm{pH}$ value was lower than 6.4, the citric acid group can combine with $\mathrm{H}^{+}$, resulting in the reduction of the chelation interaction between the citrate ion and $\mathrm{Cr}^{3+}$. This negatively influenced the aggregation process, and as a result, a decrease in sensitivity was observed.

In the case of $\mathrm{pH} 6.5$ (close to $\mathrm{p} K_{\mathrm{a} 3}$ ), citric acid exists in a trivalent anion and this has the highest ability to chelate $\mathrm{Cr}^{3+} \cdot{ }^{37}$ This $\mathrm{pH}$ resulted in an increase in the affinity of chelation between the citrate ion and $\mathrm{Cr}^{3+}$. Therefore, high aggregation will lead to a high anti-aggregation process in the studied concentration range of $\mathrm{Br}^{-}$and then maximize sensitivity. When the $\mathrm{pH}$ was increased from 7.0-7.5, the sensitivity was reduced in this system because hydrolysis of $\mathrm{Cr}^{3+}$ probably occurred, resulting in the formation of colloidal $\mathrm{Cr}(\mathrm{OH})_{3}$ that could stop the chelating reaction of the citratecapped-AuNPs with $\mathrm{Cr}^{3+} \cdot{ }^{45,46}$ Another possible reason is that $\mathrm{Br}^{-}$was likely dispersed in the alkaline environment of the solution rather than adsorbed on the AuNP surface. To obtain the maximum response of detection, a phosphate buffer of $\mathrm{pH}$ 6.5 was chosen.

3.2.3 Concentrations of the phosphate buffer. The influence of the concentration of the phosphate buffer ( $\mathrm{pH} 6.5$ ) in the range 2.5-25.0 $\mathrm{mM}$ on the aggregation and anti-aggregation of the AuNPs was performed. We investigated the effect of the buffer concentration by monitoring the change in the intensity ratio of the anti-aggregation signal from the analyte and aggregation signal from the $\mathrm{Cr}^{3+}$ (Fig. 4C), and all the obtained signals are shown in Fig. S7 (ESI $\dagger$ ). 


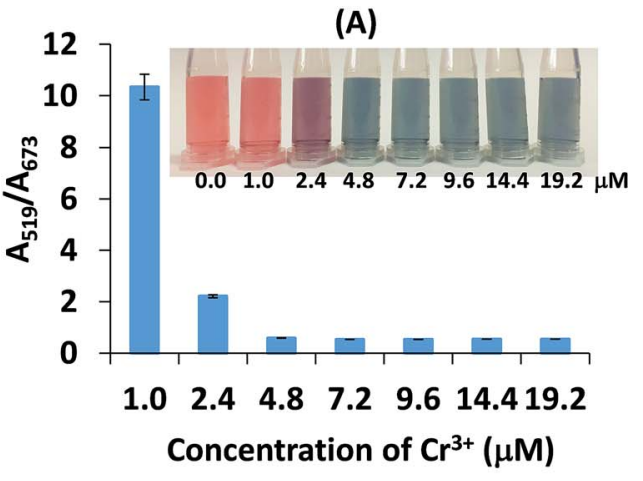

(C)

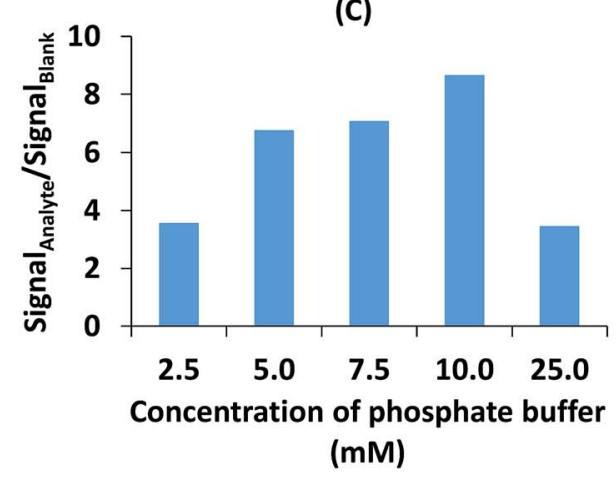

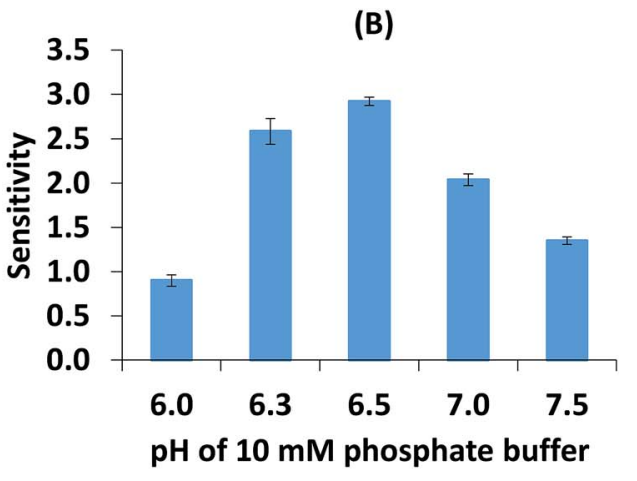

(D)

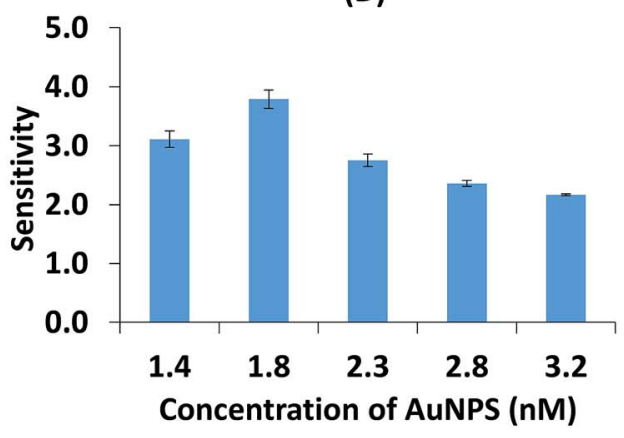

(E)

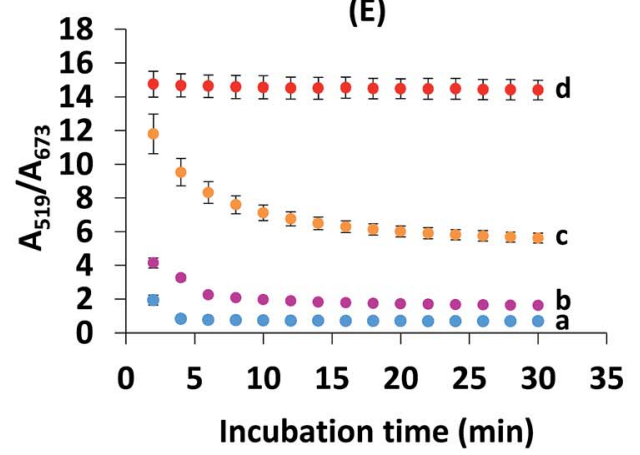

Fig. 4 Optimization of the colorimetric detection of $\mathrm{Br}^{-}$. (A) Concentration of $\mathrm{Cr}^{3+}$. (B) $\mathrm{pH}$ of $10 \mathrm{mM}$ phosphate buffer. The sensitivity was the slope of linearity plotted between the $A_{519} / A_{673}$ ratio ( $y$ axis) and the $\mathrm{Br}^{-}$concentration in the range $0.62-5.01 \mu \mathrm{M}$ ( $x$ axis). (C) Concentration of the phosphate buffer $\left(\mathrm{pH}\right.$ 6.5). The signal $\mathrm{Analyte}_{\mathrm{a}}$ and signal $\mathrm{Blank}_{\mathrm{k}}$ were the anti-aggregation signal from the analyte and aggregation signal from the $\mathrm{Cr}^{3+}$, respectively. (D) Concentration of AuNPs. The sensitivity was the slope of linearity for the $\mathrm{Br}^{-}$concentration in the range $0.63-2.50 \mu \mathrm{M}$. (E) Reaction time: (a) blank (without $\mathrm{Br}^{-}$), (b) $1.25 \mu \mathrm{M} \mathrm{Br}^{-}$, (c) $2.50 \mu \mathrm{M} \mathrm{Br}^{-}$and (d) $5.01 \mu \mathrm{M} \mathrm{Br}^{-}$.

Liu and Wang mentioned that citrate-capped AuNPs would aggregate in aqueous media with high ionic strength. ${ }^{39}$ In this study, the maximum tolerable ionic strength was found to be $10.0 \mathrm{mM}$ since this was when the maximum sensitivity was obtained. The results showed that a buffer concentration of $25.0 \mathrm{mM}$ led to a large increase in the ionic strength, which could cause the anti-aggregation to decrease and thus cause the intensity ratio to decrease. By considering the maximal ratio between the signal of the analyte and the blank, $10.0 \mathrm{mM}$ phosphate buffer ( $\mathrm{pH}$ 6.5) was chosen for the next experiment.

3.2.4 Concentrations of AuNPs. The amount of AuNPs is relative to the adsorption of $\mathrm{Br}^{-}$on the AuNP surface. If the concentration of AuNPs increases, it is necessary to increase the amount of $\mathrm{Br}^{-}$to allow for the anti-aggregation of the AuNPs.
Therefore, different final concentrations of the AuNPs ranging from 1.38 to $3.21 \mathrm{nM}$ were tested to obtain the maximum sensitivity of the $\mathrm{Br}^{-}$concentration in the range $0.63-2.50 \mu \mathrm{M}$ (Fig. 4D). This sensitivity value was the slope of linearity (Fig. S8 $(\mathrm{ESI}+))$. When the AuNP concentration was $1.38 \mathrm{nM}$, it was difficult to observe the color of the solution with the naked eye due to its faded color. The sensitivity increased to be highest in the case of $1.83 \mathrm{nM}$ AuNPs and decreased when the concentration increased above $1.83 \mathrm{nM}$ because an insufficient amount of bromide ions was adsorbed on the high abundance of AuNPs, leading to low anti-aggregation. Therefore, $1.83 \mathrm{nM}$ AuNPs was chosen.

3.2.5 Reaction time. The influence of the reaction time in the range 0-30 min on the interaction between AuNPs and $\mathrm{Br}^{-}$ 
at 1.25, 2.50 and $5.01 \mu \mathrm{M}$ was studied (Fig. 4E). It can be seen that the absorption ratio $\left(A_{519} / A_{673}\right)$ tended to decrease in the period from 0 to $10 \mathrm{~min}$ and was then stable from 10 to $30 \mathrm{~min}$. This indicated that the anti-aggregation was complete after $10 \mathrm{~min}$ of reaction time. Thus, a reaction time of $10 \mathrm{~min}$ was chosen and all further sensor measurements could be carried out within $10 \mathrm{~min}$.

\subsection{Method validation}

The concentration of bromide ions in a solution was confirmed by comparing its color and absorbance with a standard solution under the same conditions. The degree of anti-aggregation (seen by the color of solutions changing gradually from blue to red) depends on the concentration of $\mathrm{Br}^{-}$. Fig. 5 shows the absorption changes with the addition of $\mathrm{Br}^{-}$, which were further confirmed by looking at the color changes. The absorbance at 673 decreased with an increasing concentration of $\mathrm{Br}^{-}$ and the peak at $519 \mathrm{~nm}$ increased due to the anti-aggregation of the AuNPs. The absorbance ratio of $A_{519} / A_{673}$ was used for the quantitative determination of $\mathrm{Br}^{-}$since it was found to be less sensitive to changes caused by different detection conditions.

A good linearity of the standard calibration curve $y=$ $3.4803 x-0.6065, R^{2}=0.9970$ ) was found in the range 0.31-3.75 $\mu \mathrm{M} \mathrm{Br}^{-}$(Fig. 6a). The limit of detection (LOD) and limit of quantification (LOQ) were the $\mathrm{Br}^{-}$concentrations that gave a signal equal to the blank signal $(\mathrm{S} / \mathrm{N})$ plus three and ten standard deviations of the blank, respectively $(n=20){ }^{47}$ The LOD and LOQ were as low as 0.04 and $0.13 \mu \mathrm{M}$, respectively. The recovery was investigated by spiking the $\mathrm{Br}^{-}$concentrations of 12.00 to $60.00 \mathrm{mg} \mathrm{kg}^{-1}$ into composite rice samples and then testing them using our developed system. As seen in Table 1, good recoveries ranging from 79.9-92.2\% were obtained with a precision (RSD) of less than $4.0 \%(n=3)$. The inter-day precision of the three concentration levels of $\mathrm{Br}^{-}(0.63,1.25$, $3.75 \mu \mathrm{M})$ determined on each of 5 days fell between 3.07 and $7.12 \%(n=45)$, whereas the intra-day precision obtained from
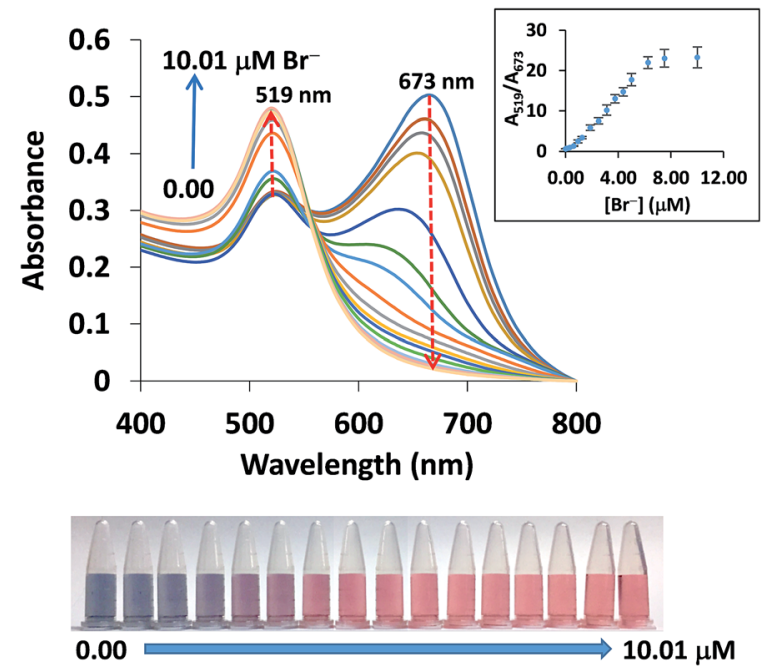

Fig. 5 UV-vis absorption spectra changes of the AuNPs in the presence of $0.00-10.01 \mu \mathrm{M} \mathrm{Br}^{-}$.

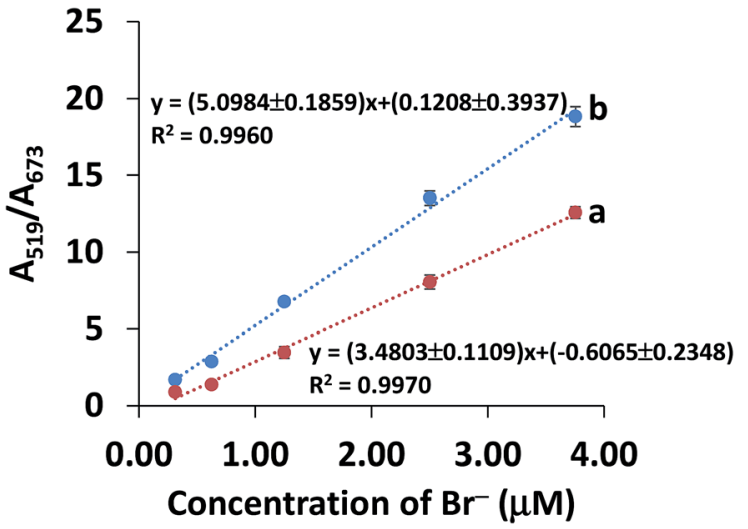

Fig. 6 Curves of (a) the standard calibration curve and (b) the standard addition curve for $\mathrm{Br}^{-}$concentration in the range $0.31-3.75 \mu \mathrm{M}$.

the 5 measurements of each of the three concentration levels on the same day ranged from $2.87-6.35 \%(n=15)$. These recoveries and precisions were acceptable within the range referred to in the AOAC standard method. ${ }^{48}$

In contrast to the aqueous standard solution, trace quantification of the analyte in real samples can suffer from the effects of the sample matrices, which can cause a positive or negative response by increasing background noise or suppressing the signal response. ${ }^{49}$ Hence, the matrix effect was investigated using a standard addition curve (Fig. 6b) in the range 0.31-3.75 $\mu \mathrm{M} \mathrm{Br}^{-}$(spiked into rice water extracts), which was compared to a standard calibration curve (Fig. 6a). As shown in Fig. 6, the sensitivity of the standard addition curve (b) was significantly different from that of the standard curve (a) $(P<0.05)$, indicating that the matrix did have an effect on the analysis of $\mathrm{Br}^{-}$in rice samples. Therefore, we used a standard addition curve for accurate determination of $\mathrm{Br}^{-}$in rice samples.

\subsection{Comparison of the developed sensor with other analytical methods}

To further demonstrate the advantages of the developed sensor, the performance of our sensor was compared with other previously reported methods. Table 2 lists the comparison results, including sample amount, linear range, LOD and detection time, of our developed sensor with other methods. The LOD and linearity obtained by our sensor were clearly superior to those obtained in the other studies. In addition, our sensor has a short detection time compared with the expensive

Table 1 Recoveries of spiked $\mathrm{Br}^{-}$in composite rice samples with relative standard deviation (RSD) values $(n=3)$

\begin{tabular}{llll}
\hline $\begin{array}{l}\text { Spiked } \\
\left(\mathrm{mg} \mathrm{kg}^{-1}\right)\end{array}$ & $\begin{array}{l}\text { Detected } \\
\left(\mathrm{mg} \mathrm{kg}^{-1}\right)\end{array}$ & Recovery (\%) & RSD (\%) \\
\hline 0.00 & $2.19 \pm 0.57$ & - & - \\
12.00 & $11.78 \pm 0.33$ & 79.94 & 2.81 \\
25.00 & $23.52 \pm 0.94$ & 85.35 & 3.98 \\
50.00 & $48.28 \pm 1.86$ & 92.19 & 3.85 \\
60.00 & $50.42 \pm 1.18$ & 80.40 & 2.35
\end{tabular}


Table 2 Comparison of the developed sensor with other methods applied for $\mathrm{Br}^{-}$determination in different samples

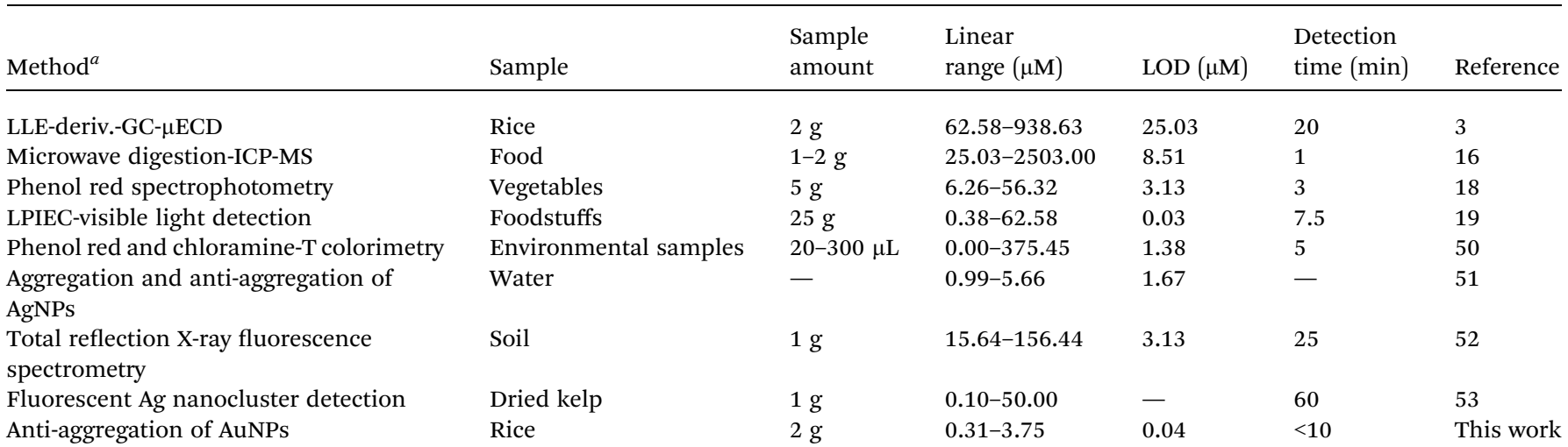

${ }^{a}$ LLE-deriv-GC- $\mu$ ECD: liquid-liquid extraction-derivatization-gas chromatography-micro electron capture detector; ICP-MS: inductive coupled plasma-mass spectrometry; LPIEC: low pressure ion-exchange chromatography.

methods.,52,53 Our sensor required a comparable amount of sample to be used for detecting $\mathrm{Br}^{-}$in real samples to the methods mentioned in Table 2. Overall, these results confirmed that our method for $\mathrm{Br}^{-}$determination based on the antiaggregation of AuNPs was more efficient and sensitive.

\subsection{Selectivity study}

Other cations and anions in rice samples were investigated as they could probably interfere with the selectivity for $\mathrm{Br}^{-}$. It was reported that inorganic anions, i.e. $\mathrm{F}^{-}, \mathrm{Cl}^{-}, \mathrm{NO}_{2}{ }^{-}, \mathrm{NO}_{3}{ }^{-}$and $\mathrm{SO}_{4}{ }^{2-}$, were found in rice samples from four provinces in China using ion chromatography, ranging from not detected to $20.90 \mathrm{mg} \mathrm{kg}^{-1} .{ }^{54}$ Some elements in rice extracts prepared using our alkaline digestion and ashing method were determined using inductively coupled plasma-optical emission spectrometry (ICP-OES) as presented in Table S1 (ESI $\dagger$ ). It was shown that

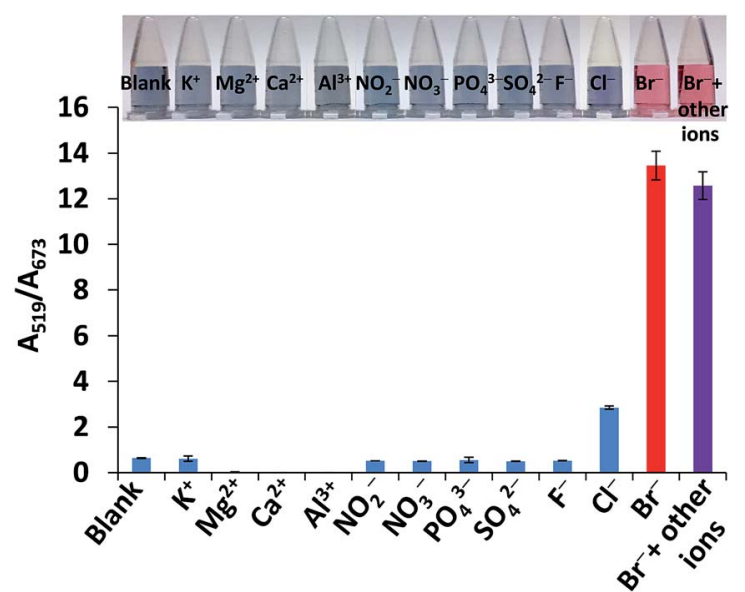

Fig. 7 Selectivity of the $\mathrm{Br}^{-}$detection. The absorbance ratio response $\left(A_{519} / A_{673}\right)$ of the proposed sensor for $5 \mu \mathrm{M} \mathrm{Br}^{-}$(red bar) was plotted against $5000 \mu \mathrm{M}$ of ion interferences $\left(\mathrm{K}^{+}, \mathrm{Mg}^{2+}, \mathrm{Ca}^{2+}, \mathrm{Al}^{3+}, \mathrm{NO}_{2}^{-}\right.$, $\mathrm{NO}_{3}{ }^{-}, \mathrm{PO}_{4}{ }^{3-}, \mathrm{SO}_{4}{ }^{2-}, \mathrm{F}^{-}$and $\mathrm{Cl}^{-}$(blue bars)) and a mixture of $\mathrm{Br}^{-}$and the other ions (violet bar). All signals corresponded to the blank. The photograph is an example of the detection sensor for $5 \mu \mathrm{M} \mathrm{Br}^{-}$, the other ions and a mixture of $\mathrm{Br}^{-}$and all the other ions. the samples had high concentrations of $\mathrm{K}, \mathrm{Mg}, \mathrm{Ca}$ and $\mathrm{P}$ in the range 6.66-13 $554.17 \mathrm{mg} \mathrm{kg}^{-1}$ whereas $\mathrm{Al}$, Cr and Se were found in low concentrations $\left(0.20-2.79 \mathrm{mg} \mathrm{kg}^{-1}\right)$. The detection of $\mathrm{K}$, $\mathrm{Ca}, \mathrm{Mg}$ and $\mathrm{Al}$ agreed with the data of other reports. ${ }^{5,56}$ Thus, the 10 common ions, i.e. $\mathrm{K}^{+}, \mathrm{Mg}^{2+}, \mathrm{Ca}^{+}, \mathrm{Al}^{3+}, \mathrm{NO}_{2}{ }^{-}, \mathrm{NO}_{3}{ }^{-}$, $\mathrm{PO}_{4}{ }^{3-}, \mathrm{SO}_{4}{ }^{2-}, \mathrm{F}^{-}, \mathrm{Cl}^{-}$, were investigated alongside $\mathrm{Br}^{-}$under the same optimal conditions. We found that $\mathrm{Cu}, \mathrm{Fe}, \mathrm{Mn}, \mathrm{Ni}$ and $\mathrm{Zn}$ were not detected, thus they were not included as interferences.

The selectivity was evaluated by testing the absorbance ratio $\left(A_{519} / A_{673}\right)$ of $5 \mu \mathrm{M} \mathrm{Br}^{-}$to $5000 \mu \mathrm{M}$ of other ions including $\mathrm{K}^{+}$, $\mathrm{Mg}^{2+}, \mathrm{Ca}^{2+}, \mathrm{Al}^{3+}, \mathrm{NO}_{2}{ }^{-}, \mathrm{NO}_{3}{ }^{-}, \mathrm{PO}_{4}{ }^{3-}, \mathrm{SO}_{4}{ }^{2-}, \mathrm{F}^{-}$and $\mathrm{Cl}^{-}$. As shown in Fig. $7, \mathrm{Br}^{-}$(red bar) showed a distinct signal whereas in the absence of $\mathrm{Br}^{-}$, the signal of the other ions except for $\mathrm{Cl}^{-}$ (blue bar) was almost identical to the blank even when their concentrations were 1000-fold higher than $\mathrm{Br}^{-}$, suggesting that no anti-aggregation of AuNPs was caused by the other ions. Furthermore, the response of $\mathrm{Br}^{-}$in the presence of a mixture of all the ions (violet bar) increased to a level similar to that of $\mathrm{Br}^{-}$ alone (red bar). This can be explained by the fact that $\mathrm{Br}^{-}$is lightly hydrated and has higher polarizability which can be attractive when it is close to the AuNP surface compared to $\mathrm{NO}_{3}{ }^{-}, \mathrm{SO}_{4}{ }^{2-}, \mathrm{F}^{-}$and $\mathrm{Cl}^{-}$while the other negative ions are repelled from the surface. ${ }^{57}$ Only the addition of $5000 \mu \mathrm{M} \mathrm{Cl}^{-}$ can result in anti-aggregation. However, considering that a low abundance of $\mathrm{Cl}^{-}$(about $3.05 \mathrm{mg} \mathrm{kg}^{-1}$ ) was detected in the rice sample matrix, the signal caused by $\mathrm{Cl}^{-}$can be ignored.

Other anions such as $\mathrm{I}^{-}, \mathrm{S}^{2-}, \mathrm{SO}_{3}{ }^{2-}$, and $\mathrm{SCN}^{-}$could affect the detection of $\mathrm{Br}^{-}$. Thus, the effect of $\mathrm{I}^{-}$and $\mathrm{SCN}^{-}$on the selectivity of the detection was investigated and the results are shown in Fig. S9 (ESI $\dagger$ ), and the responses of these ions were similar to that of $\mathrm{Br}^{-}$. This means that they interfere with the anti-aggregation of AuNPs because $\mathrm{I}^{-}$and $\mathrm{SCN}^{-}$are classified as chaotropic anions like $\mathrm{Br}^{-} .{ }^{57}$ However, $\mathrm{SCN}^{-}, \mathrm{S}^{2-}$ and $\mathrm{SO}_{3}{ }^{2-}$ have never been reported in rice samples, thus they are not of major concern for detection. It was reported that the concentration of $\mathrm{I}^{-}$is approximately 185 times lower than that of $\mathrm{Br}^{-}$in white rice samples, ${ }^{55}$ and therefore, the signal caused by the low abundance of $\mathrm{I}^{-}$in real samples can be ignored. 
These results clearly revealed that the simultaneous presence of other competitive ions even at very high concentrations did not interfere with the determination of $\mathrm{Br}^{-}$. Thus, our colorimetric sensor exhibited a high selectivity for $\mathrm{Br}^{-}$over other ions in rice samples.

\subsection{Application of the method to rice samples}

To further evaluate the feasibility of the developed sensor, five different commercial brands of white rice were collected from supermarkets and examined for $\mathrm{Br}^{-}$residues. The first attempt to prepare the rice sample was made by soaking the rice in water as a simple method and the water extract of the rice was then passed through a solid phase sorbent cartridge (Oasis HLB) and analyzed using colorimetric determination. It appeared that no significant difference in color between the unspiked and spiked sample was observed (both samples presented a red solution), indicating that the interferences, especially organic substances as well as $\mathrm{Br}^{-}$, could dissolve in aqueous extracts.

Srisawat et al. examined phenolic or flavonoid compounds in rice water extracts. ${ }^{58}$ These compounds could probably interfere with the $\mathrm{Br}^{-}$detection by: (i) adsorbing onto the surface of the AuNPs and hindering the ligand-exchange process in the $\mathrm{Cr}^{3+}$ citrate complex and (ii) forming a complex with $\mathrm{Cr}^{3+}$ instead of with the citrate. Therefore, the removal of the organic interferences is necessary.

Our sample digestion method using $1 \%$ potassium hydroxide in $50 \%$ ethanol and our ashing procedure to remove all the organic contents from the rice samples was studied and compared with an acidic digestion using hydrogen peroxide and hydrochloric acid. Metals in all the samples were analyzed using ICP-OES. As seen in Table S1 (ESI $\dagger$ ), the concentrations of other cations such as $\mathrm{Mg}^{2+}, \mathrm{Ca}^{2+}$ and $\mathrm{Al}^{3+}$ obtained using our method were much lower than those obtained via acidic digestion except that a higher amount of $\mathrm{K}^{+}$was detected. This was due to the addition of $\mathrm{KOH}$ for rice digestion; however, it has proved that $\mathrm{K}^{+}$residue does not interfere with colorimetric detection using AuNPs as shown in Fig. 7.

In addition, high recoveries for the sample preparation and detection were obtained (Table 1). Since we used a high temperature $\left(600{ }^{\circ} \mathrm{C}\right)$ for the ashing step, it was possible that $\mathrm{Br}^{-}$could evaporate, and so the remaining $\mathrm{Br}^{-}$in the samples was investigated using the $\mathrm{X}$-ray fluorescence (XRF) technique. The composite rice samples were spiked with $\mathrm{Br}^{-}$concentrations of 50,100, 200 and $400 \mathrm{M}$ and prepared as mentioned in Section 2.5. After dilution, the solution was adjusted to $\mathrm{pH} 8.0$ with $1 \mathrm{M}$ nitric acid, and was subsequently analyzed using the XRF method. Fig. S10 (ESI $\dagger$ ) shows the XRF spectra of the sample solutions spiked with $\mathrm{Br}^{-}$concentrations in the range 50-400 M. The peak signals of $\mathrm{Br}^{-}$increased with increasing $\mathrm{Br}^{-}$concentration. This confirmed that $\mathrm{Br}^{-}$will not evaporate at a temperature of $600{ }^{\circ} \mathrm{C}$. Thus, these results confirmed that our alkaline digestion and ashing method can remove some metals and organic interferences without any loss of $\mathrm{Br}^{-}$.

Whereas Sungwaranond et al. ${ }^{2}$ performed the ashing step for $8 \mathrm{~h}$, leading to a time consuming sample preparation, we further investigated the time for ashing ( 4 and $8 \mathrm{~h})$. The results
Table 3 The determination of $\mathrm{Br}^{-}$in the rice samples using the developed sensor $(n=3)$ and ion chromatography $(n=2)$, with (A) the corresponding colorimetric results and (B) a color chart for the sample sensor

\begin{tabular}{lll}
\hline & \multicolumn{2}{l}{ Found $\left(\mathrm{mg} \mathrm{kg}^{-1}\right)$} \\
\cline { 2 - 3 } Sample & Developed sensor & Ion chromatography \\
\hline White rice 1 & $3.12 \pm 0.83$ & $3.41 \pm 1.61$ \\
White rice 2 & $4.23 \pm 1.10$ & $6.25 \pm 0.80$ \\
White rice 3 & $4.07 \pm 1.70$ & $3.41 \pm 2.41$ \\
White rice 4 & $4.16 \pm 0.48$ & $4.00 \pm 2.41$ \\
White rice 5 & $5.21 \pm 0.91$ & $6.82 \pm 4.82$
\end{tabular}

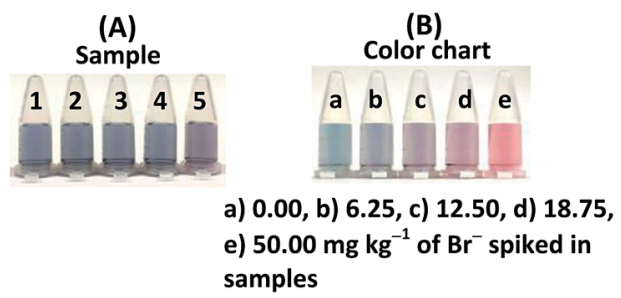

showed that statistically insignificant differences in the concentrations of cations with an ashing step of 4 and $8 \mathrm{~h}$ were observed in the samples (Table S1 (ESI $\dagger$ )). Thus, in this work, the rice samples were treated using the alkaline digestion and ashing method for $4 \mathrm{~h}$.

Table 3 shows the determination of $\mathrm{Br}^{-}$in rice samples using our sensor, together with the corresponding colorimetric results. The color chart, made by adding a $\mathrm{Br}^{-}$standard ranging from 6.25 to $50.00 \mathrm{mg} \mathrm{kg}^{-1}$ into the samples, was made for detection with the naked eye. $\mathrm{Br}^{-}$residues were detected in all the studied samples in the range $3.12-5.21 \mathrm{mg} \mathrm{kg}^{-1}$, which all fell in the range 0.00-6.25 $\mathrm{mg} \mathrm{kg}^{-1}$ shown in the color chart and were higher than those detected by Parengam et al. (0.40-1.4 mg $\left.\mathrm{kg}^{-1}\right) \cdot{ }^{55}$ However, the detectable concentrations of $\mathrm{Br}^{-}$did not exceed the MRL limit set by The Thai Ministry of Public Health (50 $\left.\mathrm{mg} \mathrm{kg}^{-1}\right){ }^{13}$ Moreover, it showed that no interferences due to co-extracted compounds were found as seen in the colorimetric results of the samples (Table 3(A)).

At present, there is no established standard method for the detection of $\mathrm{Br}^{-}$in rice samples. We have validated our developed sensor with the ion chromatographic (IC) technique (Table 3). It was found that the concentrations of $\mathrm{Br}^{-}$detected using the developed sensor were not significantly different from those detected using IC $(P>0.05)$.

These results confirmed that the developed sensor method can be used for the analysis of $\mathrm{Br}^{-}$in real complex samples.

\section{Conclusions}

We have developed a robust colorimetric sensor for bromide ions using citrate-capped AuNPs in the presence of $\mathrm{Cr}^{3+}$. The method was simple, highly sensitive and selective, and was based on the anti-aggregation induced by $\mathrm{Br}^{-}$, which results in a color change from blue to red upon the addition of different concentrations of $\mathrm{Br}^{-}$. This system presents a low LOD and LOQ 
without any noticeable interfering effects from the other components in rice samples. Satisfying recovery and precision were achieved with our developed colorimetric sensor.

\section{Conflicts of interest}

There are no conflicts of interest to declare.

\section{Acknowledgements}

This work was financially supported by the Research Assistantship (Contract No. 1-2558-02-003), Faculty of Science, Prince of Songkla University, the Department of Chemistry, the Center of Excellence for Innovation in Chemistry (PERCH-CIC), Office of the Higher Education Commission, Ministry of Education (OHEC), and the Graduate School, Prince of Songkla University.

\section{References}

1 K. N. T. Norman, Pest Manage. Sci., 2000, 56, 154-158.

2 B. Sungwaranond, P. Jongmeevasana and G. Thoophom, Bulletin of the Department of Medical Sciences, 1998, 40(2), 171-177.

$3 \mathrm{~W}$. Wittayanan and W. Jongmeevasana, Bulletin of the Department of Medical Sciences, 2015, 57(3), 219-232.

4 U.S Department of Health and Human Services, Occupational health guideline for methyl bromide, 1978, pp. 1-5.

5 United States Environmental Protection Agency (U.S. EPA), Protection of Stratospheric Ozone: Incorporation of Montreal Protocol Adjustment for a 1999 Interim Reduction in Class I, Group VI Controlled Substances. Fed. Regist., 1999, 64(104), 29240-29245.

6 W. B. Thomas, J. Nematol., 1996, 28(4S), 586-589.

7 FAO (1999) Food Agriculture Organization-World Health Organization, Codex maximum limits for pesticide residues, Codex Alimentarius Commission, FAO plant production and protection paper.

8 CCM, China reveals a list of newly banned insecticides, http://www.cnchemicals.com/Press/89543-China\%20reveals\% 20a\%20list\%20of\%20newly\%20banned\%20insecticides.html, accessed 18. 11. 2017.

9 X. Baur, L. T. Budnik, Z. Zhao, M. Bratveit, R. Djurhuus, L. Verschoor, F. M. Rubino, C. Colosio and J. R. Jepsen, J. Occup. Med. Toxicol., 2015, 10(19), 1-18.

10 M. Miyahara and Y. Saito, J. Agric. Food Chem., 1994, 42, 1126-1131.

11 D. Cova, G. F. Molinari and L. Rossini, Food Addit. Contam., 1986, 3(3), 235-240.

12 The Montreal Protocol on Substances that Deplete the Ozone Layer/Article 2H: Methyl bromide, http://www.ozone. unep.org/en/handbook-montreal-protocol-substances-depleteozone-layer/16, accessed 9. 04. 2018.

13 Notification of the Ministry of Public Health (No. 361) B.E. 2556, 2013, page 5 .

14 P. Pimpun, Methyl bromide and bromide ion, http://www. thaipan.org/sites/default/files/file/4\%20MB-Br\%20.Prapassara. pdf, accessed 4. 11. 2017.
15 A. A. Mahmoud, R. Gouda and L. Ryad, Journal of Plant Protection and Pathology, 2014, 5(11), 1015-1023.

16 T. K. D. Nguyen and R. Ludwig, Anal. Sci., 2014, 30, 10891092.

17 G. Chiu and R. D. Eubanks, Microchim. Acta, 1989, 2, 145-148.

18 E. Baso-Cejas, G. Brito, C. Díaz and E. M. Peña-Méndez, Bull. Environ. Contam. Toxicol., 2007, 78, 417-420.

19 L. Yu, X. Zhang, J. Jin, S. Che and L. Yu, Czech J. Food Sci., 2011, 29(6), 634-640.

20 Y. Zhou, H. Dong, L. Liu, M. Li, K. Xiao and M. Xu, Sens. Actuators, B, 2014, 196, 106-111.

21 Y. Li, P. Wu, H. Xu, Z. Zhang and X. Zhong, Talanta, 2011, 84, 508-512.

22 M. R. H. Nezhad and S. A. Moayed, Talanta, 2014, 129, 227232.

23 D. Liu, Z. Wang and X. Jiang, Nanoscale, 2011, 3, 1421-1433. 24 M. Zhang, Y. Q. Liu and B. C. Ye, Analyst, 2011, 136, 45584562.

25 T. Lou, L. Chen, C. Zhang, Q. Kang, H. You, D. Shen and L. Chen, Anal. Methods, 2012, 4(2), 488-491.

26 G. Wang, Z. Chen, W. Wang, B. Yan and L. Chen, Analyst, 2011, 136(1), 174-178.

27 L. Chen, W. Lu, X. Wang and L. Chen, Sens. Actuators, B, 2013, 182, 482-488.

28 Z. Zhang, J. Zhang, C. Qu, D. Pan, Z. Chen and L. Chen, Analyst, 2012, 137, 2682-2686.

29 Z. Zhang, Z. Chen, S. Wang, C. Qu and L. Chen, ACS Appl. Mater. Interfaces, 2014, 6(9), 6300-6307.

30 J. Kang, Y. Zhang, X. Li, L. Miao and A. Wu, ACS Appl. Mater. Interfaces, 2016, 8, 1-5.

31 A. Sharma, Z. Matharu, G. Sumana, P. R. Solanki, C. G. Kim and B. D. Malhotra, Thin Solid Films, 2010, 519, 1213-1218.

32 Y. Luo, J. Xu, Y. Li, H. Gao, J. Guo, F. Shen and C. Sun, Food Control, 2015, 54, 7-15.

33 M. Akhond, G. Absalan and H. Ershadifar, Spectrochim. Acta, Part A, 2015, 143, 223-229.

34 S. Kong, M. Liao, Y. Gu, N. Li, P. Wu, T. Zhang and H. He, Spectrochim. Acta, Part A, 2016, 157, 244-250.

35 J. Song, F. Wu, Y. Wan and L. Ma, Food Control, 2015, 50, 356-361.

36 M. Elavarasi, A. Rajeshwari, N. Chandrasekaran and A. Mukherjee, Anal. Methods, 2013, 5, 6211-6218.

37 A. Heller, A. Barkleit, H. Foerstendorf, S. Tsushima, K. Heim and G. Bernhard, Dalton Trans., 2012, 41, 13969-13983.

38 V. I. Kornev and G. A. Mikryukova, Russ. J. Coord. Chem., 2004, 30(12), 946-950.

39 Y. Liu and X. Wang, Anal. Methods, 2013, 5, 1442-1448.

40 C. Pfeiffer, C. Rehbock, D. Hühn, C. Carrillo-Carrion, D. J. de Aberasturi, V. Merk, S. Barcikowski and W. J. Parak, J. R. Soc., Interface, 2014, 11(20130931), 1-13.

41 G. Senanayake, Miner. Eng., 2004, 17, 785-801.

42 E. G. Vinokurov and V. V. Bondar, Russ. J. Coord. Chem., 2003, 29(1), 66-72.

43 K. Shrivas, S. Sahu, G. K. Patra, N. K. Jaiswal and R. Shankar, Anal. Methods, 2016, 8, 2088-2096.

44 M. Chen, H.-H. Cai, F. Yang, D. Lin, P.-H. Yang and J. Cai, Spectrochim. Acta, Part A, 2014, 118, 776-781. 
45 X. Wang, Y. Wei, S. Wang and L. Chen, Colloids Surf., A, 2015, 472, 57-62.

46 L. Spiccia and W. Marty, Inorg. Chem., 1986, 25, 266-271.

47 J. N. Miller and J. C. Miller, Statistics and Chemometrics for Analytical Chemistry, Pearson Education Limited, England, UK, 5th edn, 2005, Essex.

48 AOAC, Guidelines for Standard Method Performance Requirements, Appendix F, 2016, pp. 2-18.

49 T. Rujiralai, N. Raekasin, W. Cheewasedtham and C. Cheewasedtham, Chem. Pap., 2014, 68(8), 1041-1048.

50 B. J. Lepore and P. Barak, Soil Sci. Soc. Am. J., 2009, 73, 11301136.

51 S. Bothra, R. Kumar, R. K. Pati, A. Kuwar, H.-J. Choi and S. K. Sahoo, Spectrochim. Acta, Part A, 2015, 149, 122-126.

52 H. Gallardo, I. Queralt, J. Tapias, L. Candela and E. Margui, Chemosphere, 2016, 156, 294-301.
53 L. Fu, C. Li, Y. Li, S. Chen, Y. Long and R. Zeng, Sens. Actuators, B, 2017, 240, 315-321.

54 H. Sun, L. Xia, S. Liang and S. Shen, Food Analytical Methods, 2014, 7, 1791-1797.

55 M. Parengam, K. Judprasong, S. Srianujata, S. Jittinandana, S. Laoharojanaphand and A. Busamongko, J. Food Compos. Anal., 2010, 23, 340-345.

56 L. Lu, S. Tian, H. Liao, J. Zhang, X. Yang, J. M. Labavitch and W. Chen, PLoS One, 2013, 8(2), e57360.

57 V. Merk, C. Rehbock, F. Becker, U. Hagemann, H. Nienhaus and S. Barcikowski, Langmuir, 2014, 30, 4213-4222.

58 U. Srisawat, W. Panunto, N. Kaendee, S. Tanuchit, A. Itharat, N. Lerdvuthisopon and P. Hansakul, J. Med. Assoc. Thailand, 2010, 93(7), S83-S91. 